\section{Calcium, phosphor and alkaline phospatase value in bone graft calsium sulfat a-hemihydrate bioceramic application on animal bone defect (In Vivo Study)}

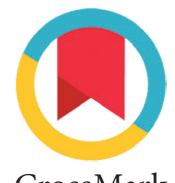

CrossMark

\author{
Bahruddin Thalib, ${ }^{1 *}$ Mochammad D. Utama, ${ }^{1}$ Edy Machmud, ${ }^{1}$ \\ Asmawati, ${ }^{2}$ Steven Winarto, ${ }^{1}$ Nur Intang ${ }^{2}$
}

\title{
Abstract
}

Objective: This study aims to determine differences in the value of calcium, phosphor, and alkaline phosphatase in the blood of bone graft material which is applied to bone defects

Methods: 12 male rabbits were divided into 4 groups, then defects were made in the femur bone with a diameter of $5 \mathrm{~mm}$. then each group was drawn with a vulnerable blood pre-operative time, 1 week, 3 weeks and 6 weeks after surgery.
Results: Average levels of calcium, alkaline phosphate and phosphorus in all treatment groups were higher than those in the control group.

Conclusion: There were differences in calcium levels in test animals using bone graft a-calcium sulphate hemihydrates bioceramic on days 7th, 21st and 42nd post surgery.
${ }^{1}$ Departement of Prosthodontic, Faculty of Dentistry, Hasanuddin University, Makassar, Indonesia ${ }^{2}$ Departement of Oral Biology, Faculty of Dentistry, Hasanuddin University, Makassar, Indonesia
${ }^{*}$ Correspondence to: Bahruddin Thalib, Departement of Prosthodontic, Faculty of Dentistry, Hasanuddin University, Makassar, Indonesia bathalib64@yahoo.com

Received: 10 May 2019 Revised: 15 August 2019 Accepted: 20 September 2019 Available Online 1 December 2019

Keywords: Bone graft, Bone loss, Calcium sulfate

Cite this Article: Thalib B, Utama MD, Machmud E, Asmawati, Winarto S, Intang N. 2019. Calcium, phosphor and alkaline phospatase value in bone graft calsium sulfat a-hemihydrate bioceramic application on animal bone defect (In Vivo Study). Journal of Dentomaxillofacial Science 4(3): 145-149. D0I: 10.15562/jdmfs.v4i3.1021

\section{Introduction}

In the field of dentistry, alveolar bone reduction can be an obstacle in making artificial teeth. ${ }^{1,2}$ Various methods of bone augmentation are done in an effort to increase bone volume. Autologous Bone Graft is the "gold standard" for bone grafting. But the amount is limited for each individual, and need to do additional operations. ${ }^{3}$ Another alternative is allograft, but it has a risk of transmission of the virus (HIV, hepatitis B, and C) from donor to recipient. ${ }^{4}$

Several alternatives have been developed for clinical use with various advantages including in the economic side. This is done by developing natural polymeric materials, synthesis, ceramics, and composites, or by combining with cells or various bone formation factors.

a-calcium sulfate hemihydrate (a-CSH, CaSO4• $0.5 \mathrm{H} 2 \mathrm{O}$ ) is a bone graft replacement, and has been widely used in dental and orthopedic surgery, with good osteoconduction characteristics, good osteoporosis, resorption rate without inflammatory response, and ability to to induce hemostasis and angiogenesis, and excellent biocompatibility. ${ }^{5}$ The latest combination of $\alpha$-calcium sulfate hemihydrate $(\alpha-\mathrm{CSH}, \mathrm{CaSO} 4 \cdot 0.5 \mathrm{H} 2 \mathrm{O})$ with bioceramics has been carried out and tested in-vitro. In-vivo testing has not been carried out on these materials, so an in-vivo test is needed by using various indicators in the process of bone formation to analyze this material. Calcium, phosphorus, and alkaline phosphotase in the blood is one indicator in the process of new bone formation.

\section{Material and Methods}

This study was conducted on 12 male rabbits, weighing 4-6 kg. Rabbits were divided into 4 groups. Group 1 (7th day interval), group 2 (21st day), group 3 (42th day), group 4 (control) each consisting of 3 animals. Surgery was performed on the lateral side of the femur bone which is made of a hole with a diameter of $5 \mathrm{~mm}$. Then the bone graft material was inserted into the bone defect, and suturing was done to the muscles and the skin. In the control group no bone graft was given on the defect that had been made. Blood samples were taken before taking action, and on the 7th, 21st, and 42th day after the operation according to the division of groups, for the control group taking blood was carried out at each time interval. Then blood samples were taken for examination and analysis of the value of calcium, phosphorus and alkaline phosphatase.

\section{Results}

All treatment groups will be presented in table 1table 6 and figure 1-figure 4 . 
Table 1 Alkaline phosphatase examination result

\begin{tabular}{lcc}
\hline Group(n=3) & Alkaline Phospatase & Control \\
\hline Pre-op & 46 & 42 \\
1 & 90 & 87.7 \\
2 & 37.7 & 36 \\
3 & 36 & 31.67 \\
\hline
\end{tabular}

Table 2 Calcium examination result

\begin{tabular}{lcc}
\hline Group(n=3) & Calcium & Control \\
\hline Pre-op & 3.57 & 3.54 \\
1 & 3.98 & 3.94 \\
2 & 3.87 & 3.79 \\
3 & 3.91 & 3.86 \\
\hline
\end{tabular}

Table 3 Phosphor examination result

\begin{tabular}{lcc}
\hline Group(n=3) & Phosphor & Control \\
\hline Pre-op & 1.52 & 1.57 \\
1 & 1.71 & 1.51 \\
2 & 2.95 & 2.85 \\
3 & 4.01 & 3.74 \\
\hline
\end{tabular}

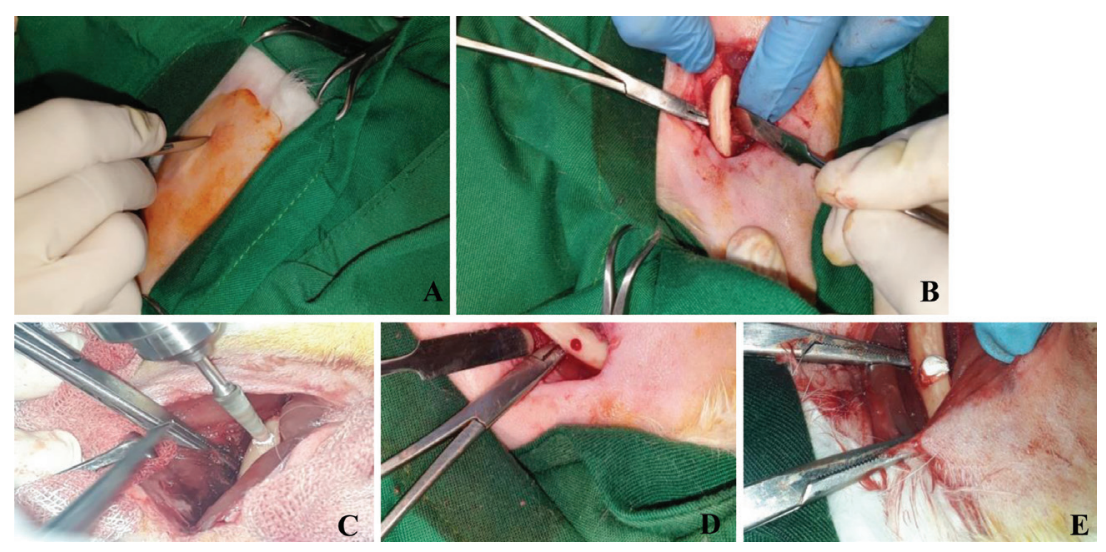

Figure 1 A. Skin incision, B. Exposed bone, C. Defect was made, D. Bone defect, E. Bone graft application

Mean of ALP

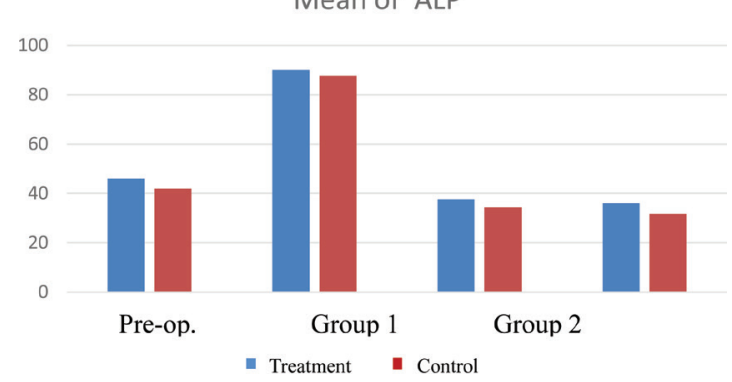

Figure 2 Mean of ALP
Mean of Calcium

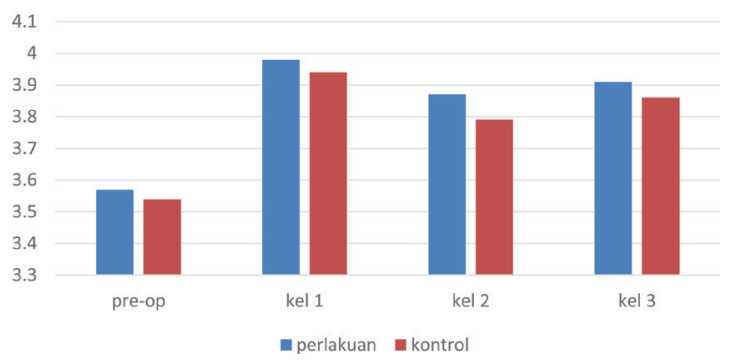

Figure 3 Mean of calcium

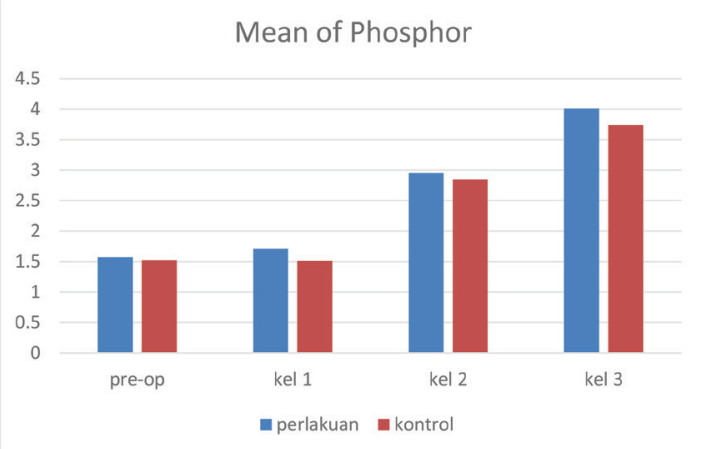

Figure 4 Mean of phosphor

\section{Discussion}

The average ALP in all treatment groups had a higher value than the control group. ALP levels increased on day 7 , but began to decrease on days 21 to day 42. That ALP is a marker of bone formation, which can be induced by the addition of a particular material as a stimulator. ${ }^{1,6}$ The difference between this study and this research is the material used in the study, which uses chitosan as a scaffold.

Significantly different comparisons were seen in the preoperative group compared with treatment on day 7, day 21, and day 42. Comparison between the preoperative group and treatment on day 7 had a significance value of $0.002(p<0.005)$ which means that there is a significant difference between ALP levels at the preoperative day 7, where there is an increase. In addition there was a significant difference between the treatment group on day 7 and treatment on day 21 , with a significance value of $0.000(p<0.05)$. There was also a significant difference between the treatment group on day 7 and the treatment group on day 42 , with a significance value of $0.000(p<0.05)$. This shows that the addition of bone graft material $\alpha$-calcium sulphate hemihydrates bioceramic has an influence in increasing the amount of ALP in the blood during bone formation.

These results indicate that there is an increase in ALP levels along with the increase in observation days. This is in line with research conducted by Saraswathy et al. ${ }^{7}$ which explained that there was 
Table 4 Analysis of ALP in blood on pra surgical day, day 7th, 21 st and 42nd

\begin{tabular}{|c|c|c|c|c|c|c|c|}
\hline ALP & (i)day & (j)day & Mean diff (i-j) & Std error & sig & Lower bound & Upper bound \\
\hline \multirow[t]{16}{*}{ Tukey HSD } & Pre OP & Day 7th & $-34.53333^{\star}$ & 6.63744 & 0.002 & -57.5231 & -11.5535 \\
\hline & & Day $21 \mathrm{st}$ & 10.13333 & 6.63744 & 0.783 & -12.8465 & 33.1131 \\
\hline & & Day 42nd & 10.80000 & 6.63744 & 0.729 & -12.1798 & 33.7798 \\
\hline & & Control & 1.80000 & 6.63744 & 1.000 & -21.1798 & 24.7798 \\
\hline & Day 7th & Pre OP & 34.53333 & 6.63744 & 0.002 & 11.5535 & 57.5253 \\
\hline & & Day 21st & $44.66667^{\star}$ & 6.63744 & 0.000 & 21.6869 & 67.6465 \\
\hline & & Day 42nd & $45.33333^{\star}$ & 6.63744 & 0.000 & 22.3535 & 68.3131 \\
\hline & & Control & -5.33333 & 6.63744 & 0.990 & -28.3131 & 17.6465 \\
\hline & Day 21st & Pre OP & -10.13333 & 6.63744 & 0.783 & -33.1131 & 12.8465 \\
\hline & & Day 7th & $-44.66667^{\star}$ & 6.63744 & 0.000 & -67.6465 & -21.6865 \\
\hline & & Day 42nd & 0.66667 & 6.63744 & 1.000 & -22.3131 & 23.6465 \\
\hline & & Kontrol & 3 & 6.63744 & 0.999 & -19.6465 & 26.3131 \\
\hline & Day 42nd & Pre OP & -10.80000 & 6.63744 & 0.729 & -33.7798 & 12.1798 \\
\hline & & Day 7th & $-45.33333^{*}$ & 6.63744 & 0.000 & -68.3131 & -22.3535 \\
\hline & & Day $21 \mathrm{st}$ & -0.66667 & 6.63744 & 1.000 & -23.6465 & 22.3131 \\
\hline & & Control & 5.33333 & 6.63744 & 0.990 & -17.6465 & 28.3131 \\
\hline
\end{tabular}

Table 5 Analysis of calsium in blood on pra surgical day, day 7th, 21 st and 42nd

\begin{tabular}{llllcccc}
\hline Calcium & (i)day & (j)day & Mean diff & Std error & sig & Lower bound & Upper bound \\
\hline \multirow{2}{*}{ Tukey HSD } & \multirow{2}{*}{ Pre OP } & Day 7th & $0.51333^{*}$ & 0.09765 & 0.002 & -0.8514 & -0.1752 \\
& & Day 21st & -0.24000 & 0.09765 & 0.279 & -0.5781 & 0.0981 \\
& & Day 42nd & $-0.44000^{*}$ & 0.09765 & 0.007 & -0.7781 & -0.1019 \\
& \multirow{4}{*}{ Day 7th } & Control & -1.0000 & 0.09765 & 0.964 & -0.4381 & 0.2381 \\
& & Pre OP & $0.51333^{*}$ & 0.09765 & 0.002 & 0.1752 & 0.8514 \\
& Day 21st & 0.27333 & 0.09765 & 0.163 & -0.0648 & 0.6114 \\
& Day 42nd & 0.07333 & 0.09765 & 0.994 & -0.2648 & 0.4114 \\
& \multirow{4}{*}{ Day 21st } & Control & 0.04000 & 0.09765 & 1.000 & -0.2981 & 0.3781 \\
& & Pre OP & 0.24000 & 0.09765 & 0.279 & -0.0981 & 0.5781 \\
& Day 7th & -0.27333 & 0.09765 & 0.163 & -0.6114 & 0.0648 \\
& & Day 42nd & -0.20000 & 0.09765 & 0.483 & -0.5381 & 0.1381 \\
& Control & -0.8667 & 0.09765 & 0.983 & -0.4248 & 0.2514 \\
& \multirow{2}{*}{ Day 42nd } & Pre OP & $0.44000^{*}$ & 0.09765 & 0.007 & 0.1019 & 0.7781 \\
& & Day 7th & -0.07333 & 0.09765 & 0.994 & -0.4114 & 0.2648 \\
& Day 21st & 0.20000 & 0.09765 & 0.483 & -0.1381 & 0.5381
\end{tabular}

an increase in the amount of ALP in bone defects induced with bone graft material in the form of bio-inorganic composites. In addition, according to Saraswathy and colleagues, an increase in ALP levels after trauma to the bone may be related to the proliferation of osteogenic cells. ${ }^{7}$ That bone formation in crystalline composites as scaffold can induce bone formation by expression of ALP markers.

Analysis of the ALP amount was carried out using the ALP assay which was read through absorbance. ${ }^{8}$ Minli X et al. ${ }^{9}$ colleagues also explained that biocomposites can stimulate bone formation through a process of mineralization mediated by ALP which appears as a marker by the presence of composite stimulation combined with calcium phosphate. ${ }^{9}$ In addition, Chen and colleagues explained that the expression of ALP, COL1, OPN, OCN and RUNX2 was very high at weeks 3 through 6 in stem cell osteogenesis 
Table 6 Analysis of phosphor in blood on pra surgical day, day 7th, 21 st and 42nd

\begin{tabular}{|c|c|c|c|c|c|c|c|}
\hline Phosphor & (i)day & (j)day & Mean diff & Std error & sig & Lower bound & Upper bound \\
\hline \multirow[t]{16}{*}{ Tukey HSD } & Pre OP & Day 7th & -0.22667 & 0.22653 & 0.968 & -1.0109 & 0.5576 \\
\hline & & Day 21st & $-1.47333^{*}$ & 0.22653 & 0.000 & -2.2576 & -0.6891 \\
\hline & & Day 42nd & $-2.53333^{\star}$ & 0.22653 & 0.000 & -3.3176 & -1.7491 \\
\hline & & Control & -0.08000 & 0.22653 & 1.000 & -0.8643 & 0.7043 \\
\hline & Day 7th & Pre OP & 0.22667 & 0.22653 & 0.968 & 0.5576 & 1.0109 \\
\hline & & Day 21st & $-1.24667^{\star}$ & 0.22653 & 0.001 & -2.0309 & -0.4624 \\
\hline & & Day 42nd & $-2.30667^{\star}$ & 0.22653 & 0.000 & -3.0909 & -1.5224 \\
\hline & & Control & 0.20000 & 0.22653 & 0.984 & -0.5843 & 0.9843 \\
\hline & Day 21st & Pre OP & $1.47333^{*}$ & 0.22653 & 0.000 & 0.6891 & 2.2576 \\
\hline & & Day 7th & $1.24667^{*}$ & 0.22653 & 0.001 & 0.4624 & 2.0309 \\
\hline & & Day 42nd & $-1.06000^{*}$ & 0.22653 & 0.005 & -1.8443 & -0.2757 \\
\hline & & Control & $2.45333^{\star}$ & 0.22653 & 1.000 & -0.6843 & 0.3757 \\
\hline & Day 42nd & Pre OP & $2.53333^{\star}$ & 0.22653 & 0.000 & 1.7224 & 3.3176 \\
\hline & & Day 7th & $2.30667^{\star}$ & 0.22653 & 0.000 & 1.5224 & 3.0909 \\
\hline & & Day 21st & $1.06000^{*}$ & 0.22653 & 0.005 & 0.2757 & 1.8443 \\
\hline & & Control & $0.27333^{\star}$ & 0.22653 & 0.918 & -0.5109 & 1.0576 \\
\hline
\end{tabular}

induced with $\alpha$-hemihydrate calcium sulphate with a combination of sodium hyaluronate. ${ }^{10-12}$ In that study, complete bone healing in the implant area around 9 weeks. That $\alpha$-calcium sulphate hemihydrates containing cerium can induce osteogenesis by the expression of alkaline phosphatase, Runx2, BSP and OCN. ${ }^{13}$ Liu and colleagues also explained that $\alpha$-calcium sulphate hemihydrates containing Strontium has the ability to repair bone through the stimulation of the expression of Runx2, alkaline phosphatase, OCN and BSP both in vitro and in vivo. $^{14}$

In the analysis of average calcium levels, it was found that all treatment groups had higher values than the control group. Calcium levels increased on day 7 , but decreased on day 21 and increased again on day 42 . This is in line with research by Saraswathy and colleagues who stated that there was a decrease in calcium levels until day 21 , but experienced an increase again in until day 42 , but not higher than calcium levels during the preoperative period. According to him, this condition is caused by increased urinary excretion after trauma to the bone.

Significant differences were only seen in two groups, namely the preoperative group with treatment on day 7 and the preoperative group with treatment group on day 42 . The preoperative group with treatment group on day 7 had significant differences with a significance value of $0.002(p<0.05)$. This shows that the increase in calcium levels from the preoperative period to the 7 th day is significant. The preoperative group with the treatment group on day 42 had a significant difference with a significance value of $0.007(\mathrm{p}<0.05)$.

That calcium levels in the preoperative period when compared to calcium levels on day 42 showed a significant significant difference, indicating that the addition of bone graft $a$-calcium sulphate hemihydrates bioceramic materials had an influence in increasing the amount of calcium in the blood during bone formation. This is different from research conducted by Saraswathy, in which the preoperative calcium level was slightly higher than on day $42 .{ }^{7}$ Research conducted by Keya et al. ${ }^{11}$ also showed mineralization at new bone encounters with the addition of $\alpha$-calcium sulphate hemihydrates, which showed increased levels of calcium ions compared to normal bone tissue. ${ }^{11}$ Liu and colleagues also obtained results in the form of elevated levels of calcium and collagen fibers in the bone which had healing until week $8 .^{14}$

At the average phosphorus level, all treatment groups had higher values than the control group. Calcium levels increased on day 7 , and continued to increase from day 21 to day 42. A significant difference was seen in the preoperative group compared with treatment on day 21 , and day 42 . In addition, there were differences significant between groups on the 7 th day with the 21st day, 7 th day with 42 nd day, and 21st day with 42nd day. Comparison between the preoperative and treatment groups on 21st day has a significance value of $0.000(\mathrm{p}<0.005)$ which means that there is a significant difference between calcium levels in the preoperative group with day $21 .^{15}$ 
In addition there was a significant difference between the treatment group in the preoperative group and the 42 nd day group, with a significance value of $0,000(p<0.05)$. There was also a significant difference between the treatment group on day 7 with the treatment group on day 21, with a significance value of $0.001(\mathrm{p}<0.05)$, and a significant difference between the treatment group on day 7 with day 42 with a significance value of $0.000(\mathrm{p}<0.05)$. In addition, there was a significant difference between the 21st day and 42nd day groups with a significance of $0.005(\mathrm{p}<0.05)$. This indicates that the addition of bone graft material a-calcium sulphate hemihydrates bioceramic has an influence in increasing the amount of phosphorus in the blood during bone formation.

This is in line with research conducted by Bonjour. ${ }^{10}$ which states that calcium and phosphorus are the two main ions that replace hydroxyapatite, bone minerals that strengthen the mechanical resistance of the organic matrix that signifies the process of bone formation. ${ }^{10}$ In line with Saraswathy's research which explains that there are increased levels phosphorus from the preoperative day to the 21 st day but decreased on day 42. This study also found conditions where there was an increase in phosphorus levels until the 21 st day. However, in contrast to his research, in this study, phosphorus levels continued to increase until the 42nd day According to him, the increase or decrease in phosphorus levels in the healing period is not significant, and the mechanism is unknown. ${ }^{7}$

\section{Conclusion}

There was a significant difference in the value of calcium, phosphorus and alkaline phosphatase in test animals using $\alpha$-calcium sulphate hemihydrates bioceramic bone graft on days 7, 21 and 42 postoperatively compared with no additional bone graft.

\section{References}

1. Beitlitum I, Artzi Z, Nemcovsky CE. Clinical evaluation of particulate allogeneic with and without autogenous bone grafts and resorbable collagen membranes for bone augmentation of atrophic alveolar ridges. Clin Oral Implants Res 2010;21: 1242-1250.

2. Ezirganli S, Kazancioglu HO, Mihmanli A, et al. Effects of different biomaterials on augmented bone volume resorptions. Clin Oral Implants Res 2015;26: 1482-1488.

3. Markel DC, Guthrie ST, Wu B, et al. Characterization of the inflammatory response to four commercial bone graft substitutes using a murine biocompatibility model. J Inflamm Res 2012;5: 13-18.

4. YK C, Nalini KB, Menon J, et al. Calcium sulfate as bone graft substitute in the treatment of osseous bone defects. A Prospec Study 2013;7: 2926-2928.

5. Hsu HJ, Waris RA, Ruslin M, et al. An innovative a-calcium sulfate hemihydrate bioceramic as a potential bone graft substitute. J Am Ceram Soc 2018;101: 419-427.

6. Thahir H, Setiawati D. Regenerative approach in the treatment of grade II furcations: a case report. J Dentomaxillofac Sci 2019;4: 55-58.

7. Saraswathy G, Sastry TP, Pal S, et al. A new bio-inorganic composite as bone grafting material: in vivo study. Trends Biomater Artif Organs 2004;17: 37-42.

8. Ruchi M, Raina DB, Ashok K. Study of in vitro and in vivo bone formation in composite cryogels and the influence of electrical stimulation. Int J Biol Sci 2015;11: 1325-1336.

9. Minli X, Magnus O, Zhibing Z, et al. Biocomposites prepared by alkaline hosphatase mediated mineralization of alginate microbeads. RSC Adv 2012;2: 1457-1465.

10. Bonjour JP. Calcium and phosphate: a duet of ions playing for bone health. J Am Coll Nutr 2011;30: 438-448

11. Keya M, Feihu Z, Fuzai C, et al. Preparation and properties of $\alpha$-calcium sulphate hemihydrates and $\beta$-tricalcium phosphate bone substitute. Bio-Med Mat Eng 2013;23: 197-210.

12. Chen C, Zhu C, Hu X, et al. a-hemihydrate calcium sulphate/pctacalcium phosphate combine with sodium hyaluronate promotes bone marrow-derived mesenchymal stem cell osteogenesis in vitro and in vivo. J Drug Design Dev Therapy 2018;12: 3269-3287.

13. Haibo X, Yu W, Hong C, et al. Cerium-containing $\alpha$-calcium sulphate hemihydrate bone substitute promotes osteogenesis. J Biomat App 2019;34: 250-260.

14. Zhi L, Zewei Y, Hong C, et al. Strontium-containing $\alpha$-calcium sulphate hemihydrate promotes bone repair via the TGF- $\beta /$ smad signalling pathway. Mol Med Rep 2019;20: 3555-3564.

15. Nainggolan LI, Gunasagaran L. Prevalence of alveolar bone deffect pattern in periodontitis patients with diabetes mellitus using bitewing radiography. J Dentomaxillofac Sci 2018;3: 88-90.

\section{Acknowledgment}

None

\section{Conflict of Interest}

The authors report no conflict of interest.

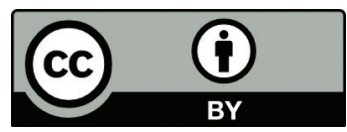

This work is licensed under a Creative Commons Attribution 